\title{
MINIMAL SCALINGS AND STRUCTURAL PROPERTIES OF SCALABLE FRAMES
}

\author{
Alice Chan, Rachel Domagalski, Yeon Hyang Kim, \\ Sivaram K. NARAYAN, Hong SuH AND Xingyu Zhang
}

Abstract. For a unit-norm frame $F=\left\{f_{i}\right\}_{i=1}^{k}$ in $\mathbb{R}^{n}$, a scaling is a vector $c=(c(1), \ldots, c(k)) \in$ $\mathbb{R}_{\geqslant 0}^{k}$ such that $\left\{\sqrt{c(i)} f_{i}\right\}_{i=1}^{k}$ is a Parseval frame in $\mathbb{R}^{n}$. If such a scaling exists, $F$ is said to be scalable. A scaling $c$ is a minimal scaling if $\left\{f_{i}: c(i)>0\right\}$ has no proper scalable subframe. In this paper, we provide an algorithm to find all possible contact points for the John's decomposition of the identity by applying the b-rule algorithm to a linear system which is associated with a scalable frame. We also give an estimate of the number of minimal scalings of a scalable frame. We provide a characterization of when minimal scalings are affinely dependent. Using this characterization, we can conclude that all strict scalings $c=(c(1), \ldots, c(k)) \in \mathbb{R}_{>0}^{k}$ of $F$ have the same structural property. That is, the collections of all tight subframes of strictly scaled frames are the same up to a permutation of the frame elements. We also present the uniqueness of orthogonal partitioning property of any set of minimal scalings, which provides all possible tight subframes of a given scaled frame.

Mathematics subject classification (2010): Primary 42C15, 05B20, 15A03.

Keywords and phrases: Frames, tight frames, diagram vectors, scalable frames, minimal scalings.

\section{REFERENCES}

[1] D. Avis And B. KaluZny, Solving Inequalities and Proving Farkas's Lemma Made Easy, Amer. Math. Monthly, 111 (2): 152-157, 2004.

[2] K. Berry, M. S. Copenhaver, E. Evert, Y. Kim, T. Klingler, S. K. Narayan, and S. T. NGHIEM, Factor posets of frames and dual frames in finite dimensions, Involve, 9 (2): 237-248, 2016.

[3] J. J. Benedetto And M. Fickus, Finite Normalized Tight Frames, Adv. Comput. Math., 18: $357-$ $385,2003$.

[4] J. CAhill AND X. Chen, A note on scalable frames, Proceedings of the 10th International Conference on Sampling Theory and Applications, 93-96, 2013.

[5] P. G. Cas azza, M. Fickus, A. Heinecke, Y. Wang, and Z. Zhou, Spectral tetris fusion frame constructions, J. Fourier Anal. Appl., 18 (4): 828-851, 2012.

[6] P. Casazza, M. Fickus, J. KovaČević, M. T. Leon, and J. C. Tremain, A physical interpretation of finite frames, Appl. Numer. Harmon. Anal., 2-3: 51-76, 2006.

[7] A. Z.-Y. Chan, M. S. Copenhaver, S. K. Narayan, L. Stokols, and A. Theobold, On Structural Decompositions of Finite Frames, Adv. Comput. Math., 42: 721-756, 2016.

[8] X. Chen, G. Kutyniok, K. A. Okoudjou, F. Philipp, And R. Wang, Measures of scalability, IEEE Trans. Inf. Theory, 61 (8): 4410-4423, 2015.

[9] M. Copenhaver, Y. Kim, C. Logan, K. Mayfield, S. K. Narayan, M. J. Petro, and J. SHEPERD, Diagram vectors and tight frame scaling in finite dimensions, Oper. Matrices, 8 (1): 78-88, 2014.

[10] M. Copenhaver, Y. Kim, C. Logan, K. Mayfield, S. K. Narayan, and J. Sheperd, Maximum Robustness and surgery of frames in finite dimensions, Linear Algebra Appl., 439 (5): 1330 1339, 2013.

[11] R. Domagalski, Y. Kim, AND S. K. NARAYAn, On minimal scalings of scalable frames, Proceedings of the 11th International Conference on Sampling Theory and Applications, 91-95, 2015. 
[12] P. P. Gruber And F. Schuster, An arithmetic proof of John's ellipsoid theorem, Arch. Math., 85 (1): 82-88, 2005.

[13] D. Han, K. Kornelson, D. Larson, And E. Weber, Frames for undergraduates, Student Mathematical Library, 40, American Mathematical Society, Providence, RI, 2007.

[14] G. Kutyniok, K. OKoudjou, And F. Philipp, Scalable frames and convex geometry, Contemp. Math., 345, 2013.

[15] G. Kutyniok, K. A. Okoudjou, F. Philipp, And E. K. Tuley, Scalable frames, Linear Algebra Appl., 438: 2225-2238, 2013.

[16] J. MatouseK, Lectures on discrete geometry, Springer, 2002.

[17] M. A. Sustik, J. A. Tropp, I. S. Dhillon, R. And W. Heath, On the existence of equiangular tight frames, Linear Algebra Appl., 426: 619-635, 2007.

[18] R. VERSHYNIN, John's decompositions: selecting a large part, Israel J. Math., 122: 253-277, 2001. 